\title{
Cross-Talk between Apolipoprotein E and Cytokines
}

\author{
Hongliang Zhang, ${ }^{1,2}$ Li-Min Wu, ${ }^{1}$ and Jiang $\mathrm{Wu}^{1}$ \\ ${ }^{1}$ Department of Neurology, The First Hospital of Jilin University, Jilin University, 130021 Changchun, China \\ ${ }^{2}$ Division of Neurodegeneration and Neuroinflammation, Department of Neurobiology, Care Sciences and Society, Karolinska Institute, \\ Karolinska University Hospital Huddinge, Novum, plan 5, 14186 Stockholm, Sweden
}

Correspondence should be addressed to Hongliang Zhang, hongliang.zhang@ki.se and Jiang Wu, sjnkwujiang@vip.sina.com

Received 13 March 2011; Accepted 2 May 2011

Academic Editor: Steven Kunkel

Copyright ( $) 2011$ Hongliang Zhang et al. This is an open access article distributed under the Creative Commons Attribution License, which permits unrestricted use, distribution, and reproduction in any medium, provided the original work is properly cited.

\begin{abstract}
Apolipoprotein E (apoE) is a multifunctional glycosylated protein characterized by its wide tissue distribution. Despite its importance in lipid transport and atherosclerosis pathogenesis, apoE is associated with neurodegenerative disorders such as Alzheimer's disease $(\mathrm{AD})$ and Parkinson disease, and autoimmune disorders such as multiple sclerosis and psoriasis. Among others, the role of apoE in modulating inflammation and oxidation is crucial in elucidating the risk factors of the above diseases since the function of apoE is closely linked with both proinflammatory and antiinflammatory cytokines. Moreover, apoE modulates inflammatory and immune responses in an isoform-dependent manner. Correspondingly, inflammatory cytokines can either upregulate or downregulate the production of apoE in various tissue types. However, studies on the interactions between apoE and cytokines occasionally yield conflicting results, highlighting the complex roles of apoE and cytokines in various disorders. The present paper summarizes the current knowledge about the cross-talk between apoE and cytokines, with emphasis on the effects of apoE on the Th1/Th2 balance.
\end{abstract}

\section{Introduction}

Apolipoprotein E (apoE) was first discovered in 1970s and identified as a component of triglyceride-rich lipoprotein complexes. Since then, apoE has been widely studied in lipid metabolism, cardiovascular diseases [1], and neurodegenerative disorders such as Alzheimer's disease (AD) [2] and Parkinson disease (PD). In addition to its well-established role in lipid transportation and atherosclerostic pathogenesis, apoE bears immunomodulatory properties and is associated with multiple sclerosis (MS) [3] and psoriasis [4]. ApoE can modulate the functions of macrophages, suppress the proliferation of $\mathrm{T}$ cells, maintain the integrity of bloodbrain barrier (BBB) and blood-nerve barrier (BNB), inhibit the proliferation of smooth muscle (SM) cells, upregulate the production of nitric oxide $(\mathrm{NO})$ of platelets, facilitate the presentation of lipid antigen by $\mathrm{CD} 1$ molecules to natural killer T (NKT) cells, and so forth, (Figure 1). Cytokines are crucial in human inflammatory and autoimmune disorders and apoE might affect these disorders through interacting with cytokines.

\section{A General View of Human ApoE, Its Polymorphism, and Its Receptors}

Human apoE is a $34.2 \mathrm{kDa}$ glycoprotein with 299 amino acid residues. ApoE is produced by liver, brain, spleen, kidney, lung and muscle tissues, and so forth. Hepatic parenchyma cells produce $2 / 3$ to $3 / 4$ of the apoE in plasma [5]. In the nervous system, apoE mRNA is present in astrocytes, microglia, Schwann cells (SCs), neurons, and so forth, (Figure 2) [6]. There are three major isoforms of human apoE (apoE2, apoE3, apoE4) encoded by the $\varepsilon 2$, $\varepsilon 3$, and $\varepsilon 4$ alleles on chromosome 19q13. Differences in the amino acid residues (positions 112/158) of apoE distinguish the apoE2 (Cys/Cys), apoE3 (Cys/Arg), and apoE4 (Arg/Arg) isoforms. The APOE $\varepsilon$ alleles show a peculiar distribution throughout the world [7]; the APOE\&3 allele is the most frequent in populations with a long-established agricultural economy, whereas the APOE\&4 allele is the ancestral allele, with a higher frequency in Pygmies, Khoi San, Papuans, Lapps, and some Native Americans [8]. The frequency of the APOE 4 allele also increases with latitude [9]. 


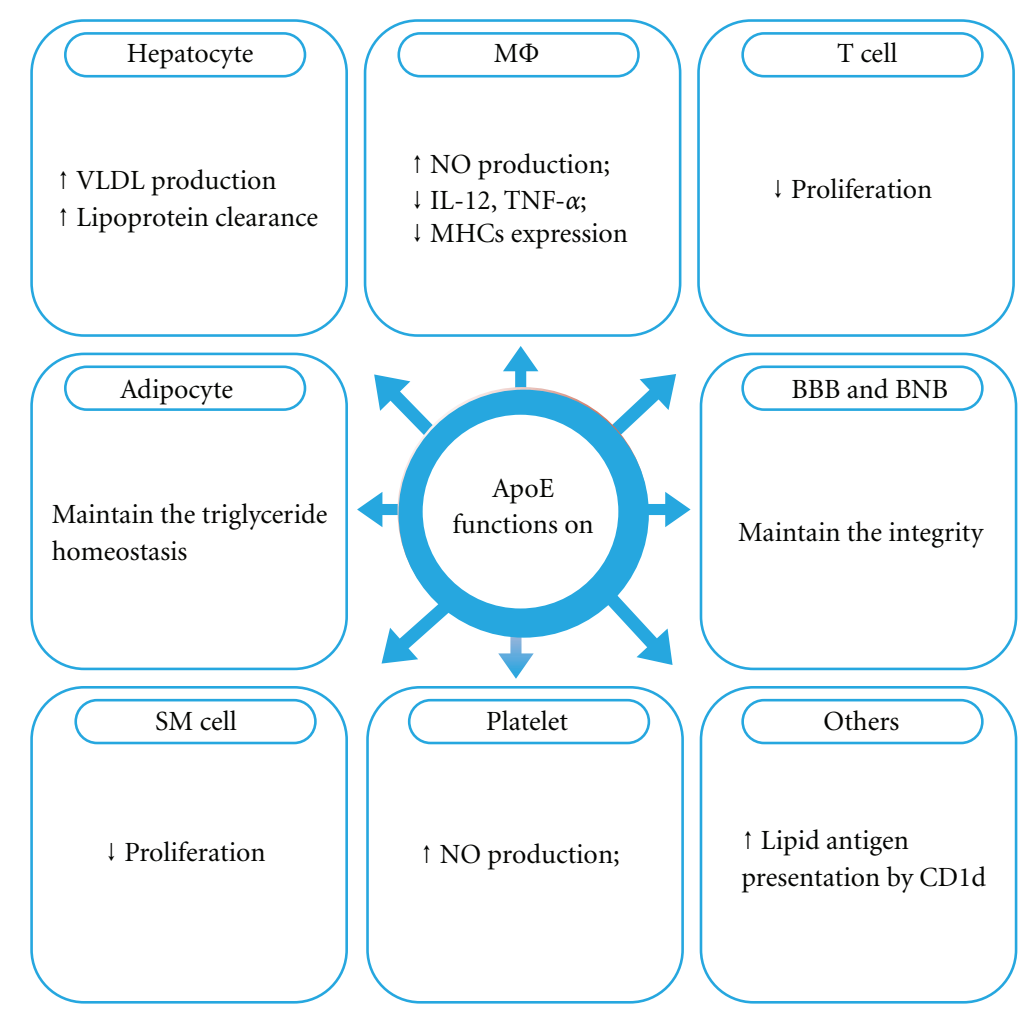

FIGURE 1: Schematic illustration of the biological properties of apoE. ApoE acts on adipocytes to maintain the triglyceride homeostasis; acts on hepatocytes to promote very low density lipoprotein (VLDL) production and lipoprotein clearance; modulates the functions of macrophages $(\mathrm{M} \Phi)$; suppresses the proliferation of T cells; maintains the integrity of blood-brain barrier (BBB) and blood-nerve barrier (BNB); inhibits the proliferation of smooth muscle (SM) cells; upregulates the production of nitric oxide (NO) of platelets; facilitates the presentation of lipid antigen by CD1 molecules to natural killer T (NKT) cells; and so forth. $\uparrow$ denotes upregulation or induction; $\downarrow$ downregulation or inhibition; IL denotes interleukin; TNF- $\alpha$ denotes tumor necrosis factor alpha; MHC denotes major histocompatibility complex.

The structural polymorphism in apoE influences its conformation and bindings to lipoprotein particles [10] and cellular receptors [11]. ApoE4 preferentially binds to lower density lipoproteins and is associated with increased risk of atherosclerosis and neurodegenerative disorders, including AD. This binding preference is due to domain interaction (the presence of Arg-112 causes Arg-61 in the amino-terminal domain to interact with Glu-255 in the carboxyl-terminal domain) (Table 1). Additionally, physiological properties of apoE, such as antioxidant [12], antiapoptotic [13], immunomodulatory [14], and atheroprotective capacities [15] are significantly influenced by apoE polymorphism.

ApoE exerts its biological functions, especially lipid transportation, by binding to its receptors, the low-density lipoprotein receptor (LDLR) family. The LDLR family includes LDLR, LDLR-related protein 1 (LRP1), very low density lipoprotein receptor (VLDLR), apoE receptor (apoER)2, megalin (also known as LRP2) and LRP1B, and so forth, [16]. As the prototype of this family, LDLR is the main receptor for cholesterol metabolism [17], to which apoE3 and apoE4 bind with 50-fold greater affinity than apoE2 [18]. ApoE is essential for the metabolism of triglyceride-rich lipoprotein constituents. The interaction of apoE and LDLR determines the removal of apoE-rich lipoproteins (VLDL, chylomicron remnants, intermediate density lipoproteins), and the homeostasis of cholesterol and triglycerides. Besides direct signal transduction, the LDLR family functions as signal modulators and integrators in several signaling pathways [19].

There is only one isoform of apoE in rodents. Murine apoE preferably associates with $\mathrm{HDL}$, and its clearance is mainly through LDLR [20].

\section{ApoE, Lipids, and Infections}

The distribution of lipids among different body compartments occurs by means of different lipoprotein particles in the blood circulation [21]. Host responses to infections involve changes in lipid levels and lipid metabolism in the plasma. These plasma lipid changes might be mediated by three cytokines interleukin (IL)-1, IL-6, and tumor necrosis factor (TNF)- $\alpha$, which induce elevated levels of triglycerides and VLDL [22], decreased levels of cholesterol, HDL and LDL $[23,24]$ or increased levels of cholesterol in the serum [25], depending on the nature of the infectious agents.

Lipoproteins and lipids present in the serum may contribute to the host innate immunity against pathogens [26]. Studies using apoE deficient mice confirmed the role of apoE in host susceptibility to endotoxemia and Klebsiella 


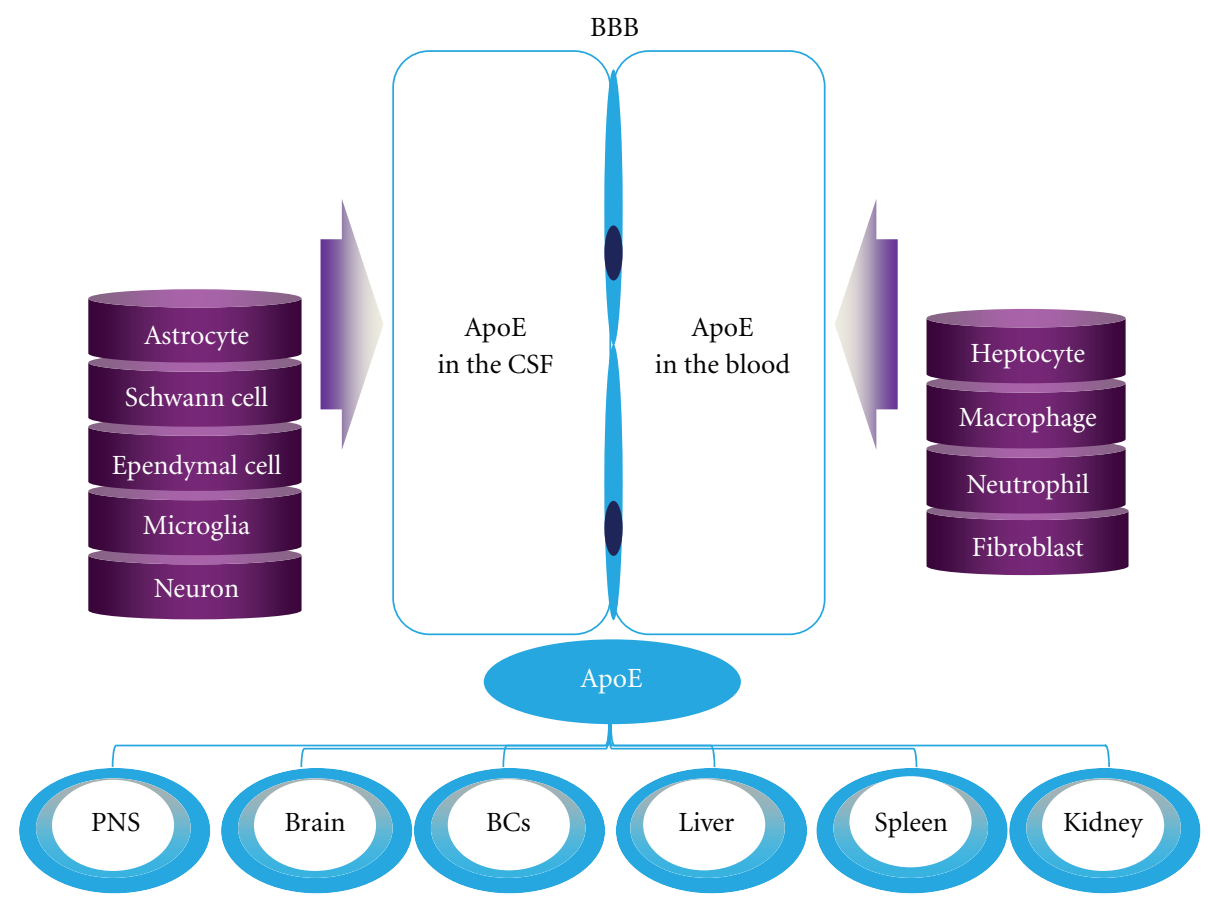

FIGURE 2: The synthesis and secretion of apoE. Hepatic parenchymal cells are the principal apoE producing cells, presumably accounting for $60 \%$ to $75 \%$ of apoE in plasma, followed by astrocytes, which are the main apoE producing cells in the nervous system. ApoE mRNA can also be found in spleen, lung, kidney, peripheral nerves, muscular tissue, adrenal, ovary and testis, and so forth. In the nervous system, apoE mRNA is present in astrocytes, nonmyelinating Schwann cells, ependymal cells, microglia, and neurons, and so forth. BCs denotes blood cells; PNS denotes peripheral nervous system; CSF denotes cerebrospinal fluid.

TABLE 1: The main differences among human apoE isoforms.

\begin{tabular}{lccccc}
\hline Isoform & \multicolumn{2}{c}{ AA residues } & Domain interaction & Binding to LDLR & Lipoprotein-binding preference \\
\hline & 112 & 158 & & & HDL \\
ApoE 2 & Cysteine & Cysteine & No & Low affinity & HDL \\
ApoE 3 & Cysteine & Arginine & No & High affinity & LDL \\
ApoE 4 & Arginine & Arginine & Yes & High affinity & \\
\hline
\end{tabular}

$\mathrm{AA}=$ amino acid

LDLR = low density lipoprotein receptor.

pneumoniae infection [27], while transgenic (Tg) mice expressing human APOE\&3 and APOE\&4 genes revealed an isoform-specific effect of apoE on the proinflammatory response to lipopolysaccharide (LPS) [28]. Infection of apoE knockout (KO) mice with Listeria monocytogenes or Klebsiella pneumoniae leads to an increased susceptibility to death as well as increased serum levels of TNF- $\alpha$ as compared with wild-type (WT) mice [29, 30]. Binding of bacterial endotoxin to either HDL, LDL, or VLDL results in a redirection of endotoxin uptake from Kupffer cells to parenchymal hepatocytes where the endotoxin is deactivated [30]. ApoE facilitated sepsis-induced mortality in a dosedependent manner and increased natural killer T-(NKT)-cell proliferation in the spleen [31]. ApoE deficient mice were markedly more susceptible to tuberculosis, evidenced by $100 \%$ mortality within 4 weeks of infection with tuberculosis [32].

ApoE $\varepsilon 4 / \varepsilon 4$ genotype was associated with an aggravated disease course of acquired immunodeficiency syndrome
(AIDS), especially with accelerated progression to death. Compared with apoE3, apoE4 enhanced human immunodeficiency virus (HIV) fusion/cell entry of both R5 and X4 HIV strains in vitro [33]. ApoE4 competes less efficiently than the other isoforms for entry into neuronal cells through heparan sulphate proteoglycan proteoglycans, which are involved in HIV attachment and entry into cells [34]. HIV produces a chronic viral infection in the central nervous system (CNS) that elicits chronic glial activation and cytokines overproduction. Corder et al. showed that HIV-infected subjects with an APOE 4 allele had excess peripheral neuropathy [35]. As a well-known risk factor for AD [2], an $\varepsilon 4$ allele along with the presence of herpes simplex virus (HSV) 1 in the brain confers an increased risk of developing to $\operatorname{AD}[36,37]$.

The production of infectious hepatitis $\mathrm{C}$ virus (HCV) was significantly reduced by the knockdown of apoE. The genotypes carrying the APOEE2 were associated with the equivalent of a 3-5-fold reduction in the risk of chronic $\mathrm{HCV}$ infection [38]. Another study, however, showed that the 
expression of the apoE2 resulted in poorer recovery of infectious HCV than did apoE3 and apoE4 isoforms [39]. Either subjects without APOE\&3 or with a single APOE\&3 with high serum cholesterol are prone to a better prognosis [40]. ApoE gene polymorphism was also associated with hepatitis $B$ virus (HBV) infection, and the $\varepsilon 2$ allele, compared with the other alleles, showed positive correlation with different $\mathrm{HBV}$ infection models [41].

\section{Effects of ApoE on the Production of Cytokines and the Maintenance of the T Helper (Th)1/Th2 Balance}

ApoE suppressed inflammation through VLDLR or apoER2 in macrophages by converting proinflammatory M1 to the antiinflammatory M2 phenotype [42]. Exogenous apoE suppressed LPS and polyinosine-polycytidylic acid (PIC, a double-stranded RNA that serves as a viral mimetic and a Toll-like receptor (TLR)3 agonist) induced secretion of IL-6, IL- $1 \beta$ and TNF- $\alpha$ by RAW 264.7 cells via repressing TLR-agonist-induced phosphorylation of c-Jun N-terminal kinase (JNK) and c-Jun. ApoE peptide (141-155)2 inhibits LPS- and PIC-induced macrophage inflammatory responses in a similar manner [43]. ApoE also reduces inflammatory signaling in astrocytes and microglia in response to proinflammatory stimuli $[44,45]$.

Th precursor (THP) cells can differentiate into Th1, Th2, or Th0 cells. Th0 cells can differentiate to Th1 and Th2 subpopulations depending primarily on the cytokines provided exogenously or from dendritic cells. Th1 cells are involved in cellular immunity and immunoglobulin class switching to the IgG2a isotype, whereas Th2 cells are mainly associated with humoral immunity and immunoglobulin class switching to IgG1 and IgE. Moreover, Th1 cells promote the induction of complement-fixing, opsonizing antibodies and of antibodies involved in antibody-dependent cell cytotoxicity, for example, IgG2a in mice. Th1 cytokines include interferon (IFN) $-\gamma$, IL-12, and TNF- $\alpha$. They can activate macrophages to produce reactive oxygen intermediates and NO, stimulate their phagocytic functions, and enhance their antigen presenting capacity by upregulating major histocompatibility complex (MHC) class molecules. Th2 cytokines include IL-4, IL-5, IL-10, and IL-13, which provide potent help for B-cell activation, immunoglobulin class switching to IgE and IgG1 in the mouse, and downregulation of macrophage activation (Figure 3 ).

Imbalance of the Th1/Th2 can result in autoimmune disorders. In experimental autoimmune neuritis (EAN), an animal model of human Guillain-Barré syndrome (GBS), Th1 cytokines predominate and mediate inflammatory damage to the peripheral nerves, whereas Th2 cytokines are associated with recovery from the disease [46-48]. Proinflammatory cytokines such as IL-1 $\beta$, IL-6, IL-12, IL-17, IL-18, IL-23, TNF- $\alpha$, IFN- $\gamma$, and macrophage inhibitory factor (MIF) significantly contribute to disease development of EAN by recruiting effector cells to the peripheral nervous system (PNS) and by enabling in situ release of other products toxic for SCs and myelin such as free radicals, oxygen intermediates, and NO [46, 47, 49-51]. Antiinflammatory cytokines from Th2 cells such as IL- 4 and IL-10 may suppress the disease by playing an important antiinflammatory role $[52,53]$. The balance of functionally distinct T-cell subsets between Th1 and Th2 has a direct relevance to autoimmune disorders.

Recently, the Th1/Th2 paradigm has been challenged, following the discovery of a third subset of effector Th cells that produce IL-17 (termed Th17 cells) and exhibit effector functions distinct from Th1 and Th2 cells. Th17 cells are potent inducers of tissue inflammation and have been associated with the pathogenesis of many autoimmune diseases and rheumatic disorders [54]. IL17-producing Th17 cells have been found to play an important role in many autoimmune diseases including experimental autoimmune encephalomyelitis (EAE), an animal of MS, while thymic regulatory $\mathrm{T}$ (Treg) cells have a suppressive role, although their roles in EAN and GBS need further investigation [55]. Increased mRNA level of IL- $1 \beta$, IL- 2 , IL- 6 , IFN- $\gamma$, intercellular adhesion molecule (ICAM)-1, vascular cell adhesion molecule (VCAM)-1, monocyte chemoattractant protein (MCP)-1, nuclear factor (NF) $\kappa \mathrm{B}(\mathrm{p} 65)$ and inhibitory $(\mathrm{I}) \kappa \mathrm{B}-$ $\alpha$ and decreased mRNA level of IL-4, IL-10, and granulocytemacrophage colony-stimulating factor (GM-CSF) in apoE $\mathrm{KO}$ mice compared with WT mice imply that lacking apoE promotes Th1 immune responses by changing these cytokines [56]. IL-6, IL-12, TNF- $\alpha$, and IFN- $\gamma$ were upregulated to a significantly greater level in apoE-deficient mice than in WT mice at both the mRNA and protein levels in response to LPS administration. ApoE selectively regulates TLR4- and TLR3-mediated signaling of IL-12 production and apoE may suppress the Th1 immune response by modulating IL-12 production [57]. Macrophages from apoEdeficient mice stimulated by exogenous antigens are more effective in upregulating MHC class molecules and CD80, with elevated secretion of IFN- $\gamma$ in responding $\mathrm{T}$ cells [58]. Severe hypercholesterolemia can induce a switch of autoimmune responses from Th1 to Th2 effector type in atherosclerotic apoE KO mice [59]. ApoE-deficient mice injected with LPS produced elevated levels of IL- $1 \beta$, IL- 6 , and TNF- $\alpha$, when compared with WT mice, and exogenous apoE could reverse this effect [60].

ApoE targets myeloid differentiation primary response gene $(\mathrm{MyD}) 88$ and interleukin-1 receptor-associated kinase (IRAK) 1 activation whereby interrupting IL- $1 \beta$ and IL-18 signaling in vascular smooth muscle cells (VSMCs). As a consequence, apoE can inhibit VSMC activation in response to IL-18. IL- $1 \beta$ signaling intermediates $\mathrm{NF} \kappa \mathrm{B}$ transactivation was inhibited by apoE in MyD88- and IRAK1- but not in TRAF6-transfected cells. ApoE can prevent IRAK1 phosphorylation and IRAK1-TRAF6 but not MyD88-IRAK1 complex formation [61].

$\mathrm{NO}$ is a principal effector of macrophage-mediated inflammatory/immune responses. In the mononuclearphagocyte system, NO is formed enzymatically from Larginine by inducible nitric oxide synthase (iNOS) [62]. Treatment of microglia and peripheral macrophages with apoE increased NO production stimulated by IFN- $\gamma$ and LPS [63]. ApoE per se, however, seems unable alone to induce the 


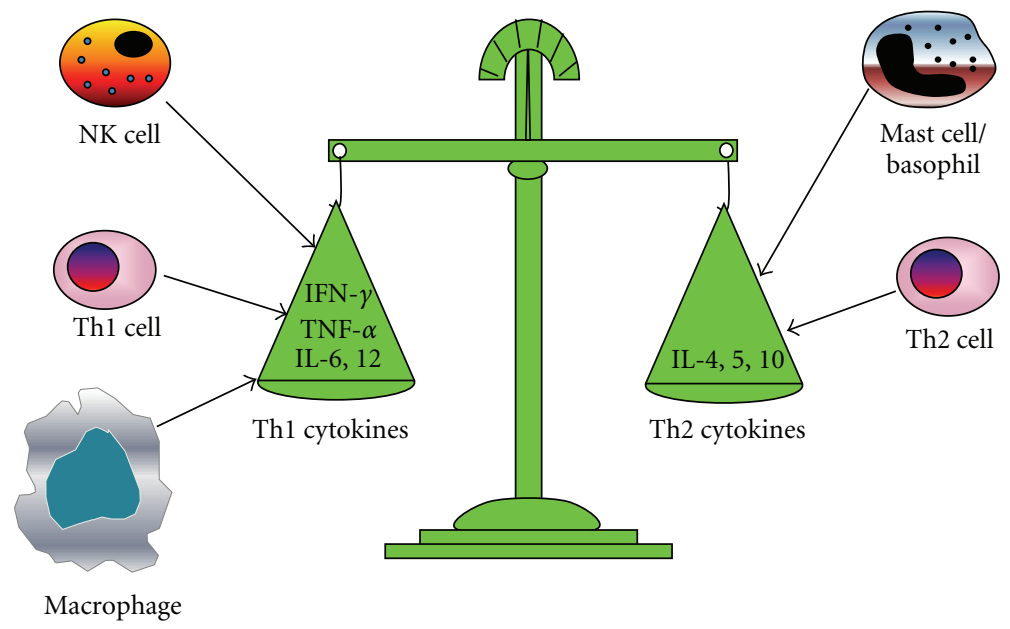

FIgURE 3: The T helper (Th)1/Th2 balance. Th1 cytokines, characterized by the production of interferon (IFN)- $\gamma$ and interleukin (IL)-6, are involved in cellular immunity and immunoglobulin class switching to the IgG2a isotype, whereas Th2 cytokines, characterized by IL-4 and IL-10, are mainly associated with humoral immunity and immunoglobulin class switching to IgG1 and IgE. Th1 cells are the primary Th1 cytokine producing cells. Besides, natural killer (NK) cells and macrophage also contribute to the production of Th1 cytokines. Similarly, Th2 cells produce the most Th2 cytokines in addition to mast cells and basophils. TNF- $\alpha$ denotes tumor necrosis factor alpha.

production of either iNOS; it functions via alteration of arginine availability [64]. Furthermore, upon proinflammatory stimulation, peripheral macrophages from male APOE\&4 $\mathrm{Tg}$ mice could produce significantly higher levels of $\mathrm{NO}$ than from APOEE3 Tg mice [65]. Similar results were also found in human studies [66]. The elevated NO production is coupled with an increased arginine uptake in male APOE\&4 $\mathrm{Tg}$ mice and is dependent on p38 mitogen-activited protein kinase (MAPK) [67], whereas it is not the case in female mice. Macrophages from female APOE Tg mice produce higher levels of NO than male ones, without any isoformdependent differences [68].

SCs can secrete cytokines like IL-6 and IL-10 and actively participate in immune responses as facultative antigen presenting cells in the PNS [69]. The antigen presenting properties of SCs were enhanced in apoE KO mice, concomitant with downregulated production of intracellular IL-6 [70]. In the recovery stage of EAN, NO produced by SCs is pivotal for the termination of local immune responses by inducing apoptosis of effector T cells in the PNS [65]. ApoE may regulate local inflammation in the PNS via modulating cytokine and $\mathrm{NO}$ production. ApoE might act as an inhibitor for EAN by suppressing the Th1 response and shifting the Th1/Th2 to the Th2 direction. An increased susceptibility to EAN after upregulation of the autoreactive T-cell response to peripheral nerve component with higher levels of IFN- $\gamma$, IL12 , and TNF- $\alpha$ and lower levels of IL-10 was seen in apoE KO mice than WT mice [71].

Significantly increased secretion of Th17-related cytokines (IL-17 and IL-6) and expression of transcription factor retinoid-related orphan receptor gamma $(\operatorname{ROR} \gamma) \mathrm{t}$ levels and obviously decreased number in Treg cells, secretion of Tregrelated cytokines (TGF- $\beta 1$ ) and expression of transcription factor (Foxp3) levels were found in apoE KO mice. Th17/Treg functional imbalance exists in apoE $\mathrm{KO}$ mice, suggesting a role of Th17/Treg imbalance in apoE functioning [72]. IL$17 \mathrm{~A}$ was also found to be elevated in the plasma and tissues of apoE null mice [73].

COG133, a mimetic of apoE protein, when binding to a protein transduction domain creates COG112, an antennapedia-linked apoE-mimetic peptide, improves therapeutic effects on EAE through decreasing demyelination and diminishing the number of peripheral cells infiltrating into the spinal cord, as well as other inflammatory processes $[74,75]$. Increased mRNA level of iNOS, TNF- $\alpha$, IFN- $\gamma$, and IL-17 and decreased nuclear translocation of NF- $\kappa$ B and $\mathrm{I} \kappa \mathrm{B}$ kinase $(\mathrm{IKK})$ activity in colitis models suggest that COG112 inhibits inflammation through the $\mathrm{NF} \kappa \mathrm{B}$ pathway [76]. Furthermore, intravenous administration of a small apoE-mimetic peptide derived from the receptor-binding region of the apoE holoprotein (apoE-(133-149)) similarly suppressed both systemic and local brain inflammatory responses in mice after LPS administration [28]. However, different genetic basis determines modified immunological processes [77].

ApoE plays its nonlipid related roles by binding to cell surface receptors [78]. LRP is implicated to mediate the immunomodulatory effects of apoE, although there seems to be no difference in the binding affinity of apoE isoforms to $\operatorname{LRP}[79,80]$.

\section{Isoform-Dependent Effects of ApoE on the Production of Cytokines}

ApoE suppressed the secretion of TNF- $\alpha$ and IL- $1 \beta$ in an isoform-specific fashion (E2 > E3 > E4) [67]. A markedly higher level of TNF- $\alpha$ was observed in supernatant of cultured macrophage derived from adult male APOE 4 Tg mice compared with macrophages from APOE\&3 ones [81]. 
In the presence of LPS, apoE3-expressing cells produce less TNF- $\alpha$ and IL-6 than apoE2 and apoE4-expressing cells which might be related with the extracellular signal-regulated kinases (ERK)1/2 signaling pathways [82]. ApoE genotype pronouncedly affects the cellular immune response in stably transfected murine macrophages. In apoE4 versus apoE3 macrophage cell line cells higher levels of proinflammatory cytokines including TNF- $\alpha$ appeared evident followed by LPS stimulation [83]. Preincubation with human recombinant apoE blocked glial secretion of TNF- $\alpha$ in mixed neuronglial cultures in response to LPS stimulation in a dosedependent manner (apoE3 > apoE4). This effect was the greatest when apoE was preincubated for 24 hours and was not dependent on any direct effect of apoE on cell viability [84].

Twice as many apoE4 carriers were demented (30\% versus $15 \%$ ) or had peripheral neuropathy as compared with non-apoE4 carriers in the HIV infection [35]. If there are apoE isoform-dependent differences in the antiinflammatory function of apoE in vivo, such differences might in part explain the differential risk for $\mathrm{AD}$ caused by apoE isoforms. However, several studies demonstrated that exogenously applied apoE4 had robust proinflammatory activity in astrocytes and microglial cells $[85,86]$. In mice receiving the basal diet without quercetin supplementation, levels of TNF- $\alpha$ in whole blood stimulated ex vivo with LPS were higher in apoE3 than apoE4 Tg mice [87].

ApoE displayed an isoform-specific effect on inflammation in primary adult microglia culture, with apoE4 the most potent to stimulate production of prostaglandin-E2 and IL-1 $\beta$ [88]. Activation of primary astrocytes from APOE targeted replacement (TR) mice with LPS led to genotypedependent differences in cytokine secretion that were the greatest in APOE\&2 TR mice (APOE2 > APOE3 > APOE4) [89]. Activation of primary astrocytes from APOE TR mice with LPS led to APOE-dependent differences in cytokine secretion that were greatest in APOE\&2 TR mice and that were associated with differences in $\mathrm{NF} \kappa \mathrm{B}$ subunit activity [89].

Transforming growth factor (TGF)- $\beta 1$ contains similar structure with apoE and lipoproteins containing the apoE3 isoform have higher TGF- $\beta$ levels and bioactivity than those containing apoE4. Association of TGF- $\beta$ with different types of lipoproteins may be beneficial to diseases like atherosclerosis and $\mathrm{AD}[90]$.

Intraventricular administration of LPS resulted in higher production of proinflammatory cytokines, along with greater activation of $\mathrm{NF} \kappa \mathrm{B}$-regulated genes in the apoE4 than in apoE3 Tg mice [91]. Inflammatory responses of APOE\&4 TR mice following intravenous administration of LPS expressing the human APOE\&4 allele had higher systemic and brain levels of the proinflammatory cytokines TNF- $\alpha$ and IL6 than their apoE3 counterparts, suggesting an isoformspecific effect of the immunomodulatory properties of apoE [28].

COG1410, an apoE-mimetic peptide, was also associated with a reduction in TNF- $\alpha$, IL- $1 \beta$, IL-6, and IL- 12 levels in both apoE3 TR and apoE4 TR mice assessed at 24 hours in the caecal ligation and puncture model of peritonitis [92].
Peripheral blood mononuclear cells (PBMCs) from AD patients with APOE 44 allele produced higher spontaneous and phorbol-12-myristate-13-acetate-(PMA-) induced levels of IL- $1 \beta$ after controlling for confounders. APOE $4 \varepsilon$ carriers showed higher concentrations of IL- $1 \beta$ than their counterparts without APOE\&4 after PMA-stimulation [93]. The APOE 4 allele was associated with lower serum levels of IL-10 in both acute coronary syndrome and chronic stable angina patients [94]. Recombinant apoE suppresses chemokine ( $\mathrm{C}-\mathrm{C}$ motif) ligand (CCL) 2 and vascular endothelial growth factor (VEGF) expression in retinal pigment epithelium (RPE) cells in an isoform-dependent manner (apoE4 $>$ apoE3) [95]. The exact molecular mechanisms by which apoE isoforms differentially alter the immune responses have been postulated to influence different signaling pathways. ApoE isoforms might be in part responsible for the differential modulation of $\mathrm{NF} \kappa \mathrm{B}$ and MAPK pathways $[89,91,96]$.

A significant interaction between APOE genotype and the response to $17 \beta$-estradiol was observed for $\mathrm{NO}$ and TNF- $\alpha$ production from microglia activated by recombinant mouse IFN- $\gamma$ plus either LPS or PIC. The antiinflammatory activity of $17 \beta$-estradiol is pronouncedly reduced in APOE $\varepsilon 4$ TR mice compared with APOE\&3 TR mice. ApoE genotype may affect the neuroprotective role of $17 \beta$-estradiol and of hormone replacement therapy on brain function when the $\mathrm{APOE} 4$ gene is expressed [96].

\section{Effects of Cytokines on the Production of ApoE in Various Tissues}

Classical activation of macrophages by proinflammatory cytokines such as IFN- $\gamma$ and TNF- $\alpha$ can downregulate apoE production [97-99]. However, antiinflammatory stimuli such as TGF- $\beta$ and estrogen promote apoE synthesis and release [100]. GM-CSF stimulated macrophages had a 3-5-fold reduction in apoE secretion, comparable with that observed for IFN- $\gamma$, while TNF- $\alpha$ and IL- $1 \beta$ resulted in a $2-$ fold decrease. In contrast to the reduction in apoE secretion by these cytokines, TGF- $\beta$ stimulated macrophages secreted 3 -fold greater amounts of apoE than controls [100-103].

Treatment of primary rat astrocyte and mixed glial cell cultures with TNF- $\alpha$ markedly reduced extracellular apoE protein levels [104]. The effects of apoE in adipose tissue on body lipid homeostasis and atherosclerosis have been widely studied [105]. ApoE is important in modulating triglyceride metabolism in adipocytes. TNF- $\alpha$ can suppress the synthesis of apoE in adipocytes [106]. TNF- $\alpha$ may activate the binding of $\mathrm{NF} \kappa \mathrm{B}$ p50 to a binding site at -43 in the apoE promoter. Treatment of adipocytes with TNF- $\alpha$ led to increased binding of $\mathrm{NF} \kappa \mathrm{B}$ p50, decreased binding of p65 and Sp1 to this region of the apoE promoter, and repression of adipocyte apoE gene expression. Reduction of p50 expression using siRNA completely eliminated TNF- $\alpha$-mediated reduction of endogenous apoE gene expression in adipocytes [107].

IFN- $\gamma$ dramatically increased the degradation of intracellular apoE and inhibited the accumulation of apoE in the supernatants of human monocyte-derived macrophages and human acute monocytic leukemia cell line (THP-1) cells via post-translational modification of apoE $[97,108]$. IFN- $\beta 1 b$ 
has inhibitory effects on the production of apoE mRNA, cellular protein, and secreted protein in blood monocytes [109]. Treatment of primary mixed glial cell cultures with IL- $1 \beta$ induced a marked increase of extracellular apoE protein. TGF- $\beta$ can induce the expression of apoE in the THP1 cell line by activating JNK, MAPK p38 and caseine kinase (CK)2 pathways. Pharmacological inhibitors can prevent this action [110].

\section{Concluding Remarks}

ApoE plays a pivotal role in maintaining the Th1/Th2 balance. Exogenous apoE suppressed the production of proinflammatory cytokines in an isoform-specific manner. Classical activation of macrophages by proinflammatory cytokines can downregulate apoE production and antiinflammatory stimuli can promote apoE synthesis and release, indicating a key role of apoE and cytokines in immunomodulation. ApoE suppressing proinflammatory signalings, and vice versa, indicate an intricate apoE-mediated feedback regulation of inflammatory and immune responses.

\section{Acknowledgment}

This work was supported by grants from the China Scholarship Council.

\section{References}

[1] D. S. Knopman, R. O. Roberts, Y. E. Geda et al., "Association of prior stroke with cognitive function and cognitive impairment: a population-based study," Archives of Neurology, vol. 66, no. 5, pp. 614-619, 2009.

[2] J. Kim, J. M. Basak, and D. M. Holtzman, "The role of apolipoprotein E in Alzheimer's disease," Neuron, vol. 63, no. 3, pp. 287-303, 2009.

[3] J. Shi, C. B. Zhao, T. L. Vollmer, T. M. Tyry, and S. M. Kuniyoshi, "APOE $\varepsilon 4$ allele is associated with cognitive impairment in patients with multiple sclerosis," Neurology, vol. 70, no. 3, pp. 185-190, 2008.

[4] P. Coto-Segura, E. Coto, V. Alvarez et al., "Apolipoprotein $\varepsilon 4$ allele is associated with psoriasis severity," Archives of Dermatological Research, vol. 302, no. 2, pp. 145-149, 2010.

[5] R. W. Mahley, "Apolipoprotein E: cholesterol transport protein with expanding role in cell biology," Science, vol. 240, no. 4852, pp. 622-630, 1988.

[6] L. M. Refolo and H. M. Fillit, "Apolipoprotein E4 as a target for developing new therapeutics for Alzheimer's disease," Journal of Molecular Neuroscience, vol. 23, no. 3, pp. 151-155, 2004.

[7] R. M. Corbo and R. Scacchp, "Apolipoprotein E (APOE) allele distribution in the world. Is APOE* 4 a 'thrifty' allele?" Annals of Human Genetics, vol. 63, no. 4, pp. 301-310, 1999.

[8] M. Takeda, R. Martínez, T. Kudo et al., "Apolipoprotein $\mathrm{E}$ and central nervous system disorders: reviews of clinical findings," Psychiatry and Clinical Neurosciences, vol. 64, no. 6, pp. 592-607, 2010.

[9] L. Ulrik Gerdes, "The common polymorphism of apolipoprotein E: geographical aspects and new pathophysiological relations," Clinical Chemistry and Laboratory Medicine, vol. 41, no. 5, pp. 628-631, 2003.
[10] J. S. Gong, S. Y. Morita, M. Kobayashi et al., "Novel action of apolipoprotein e (ApoE): ApoE isoform specifically inhibits lipid-particle-mediated cholesterol release from neurons," Molecular Neurodegeneration, vol. 2, no. 1, article no. 9, 2007.

[11] E. Hone, I. J. Martins, M. Jeoung, T. H. Ji, S. E. Gandy, and R. N. Martins, "Alzheimer's disease amyloid-beta peptide modulates apolipoprotein E isoform specific receptor binding," Journal of Alzheimer's Disease, vol. 7, no. 4, pp. 303-314, 2005.

[12] C. M. Lauderback, J. Kanski, J. M. Hackett, N. Maeda, M. S. Kindy, and D. A. Butterfield, "Apolipoprotein E modulates Alzheimer's A $\beta$ (1-42)-induced oxidative damage to synaptosomes in an allele-specific manner," Brain Research, vol. 924, no. 1, pp. 90-97, 2002.

[13] Z. S. Ji, K. Müllendorff, I. H. Cheng, R. D. Miranda, Y. Huang, and R. W. Mahley, "Reactivity of apolipoprotein E4 and amyloid $\beta$ peptide: lysosomal stability and neurodegeneration," The Journal of Biological Chemistry, vol. 281, no. 5, pp. 26832692, 2006.

[14] H. L. Zhang, J. Wu, and J. Zhu, "The role of apolipoprotein E in Guillain-Barré syndrome and experimental autoimmune neuritis," Journal of Biomedicine \& Biotechnology, vol. 2010, Article ID 357412, 12 pages, 2010.

[15] R. DeKroon, J. B. Robinette, A. B. Hjelmeland et al., "APOE4VLDL inhibits the HDL-activated phosphatidylinositol 3kinase/Akt pathway via the phosphoinositol phosphatase SHIP2," Circulation Research, vol. 99, no. 8, pp. 829-836, 2006.

[16] G. Bu, "Apolipoprotein E and its receptors in Alzheimer's disease: pathways, pathogenesis and therapy," Nature Reviews Neuroscience, vol. 10, no. 5, pp. 333-344, 2009.

[17] T. Yamamoto, H. W. Choi, and R. O. Ryan, "Apolipoprotein $\mathrm{E}$ isoform-specific binding to the low-density lipoprotein receptor," Analytical Biochemistry, vol. 372, no. 2, pp. 222226, 2008.

[18] R. L. Raffaï, L. M. Dong, R. V. Farese, and K. H. Weisgraber, "Introduction of human apolipoprotein E4 "domain interaction" into mouse apolipoprotein E," Proceedings of the National Academy of Sciences of the United States of America, vol. 98, no. 20, pp. 11587-11591, 2001.

[19] J. Herz, "Apolipoprotein E receptors in the nervous system," Current Opinion in Lipidology, vol. 20, no. 3, pp. 190-196, 2009.

[20] L. Li, P. A. Thompson, and R. L. Kitchens, "Infection induces a positive acute phase apolipoprotein E response from a negative acute phase gene: role of hepatic LDL receptors," Journal of Lipid Research, vol. 49, no. 8, pp. 1782-1793, 2008.

[21] N. Urosevic and R. N. Martins, "Infection and Alzheimer's disease: the APOE $\varepsilon 4$ connection and lipid metabolism," Journal of Alzheimer's Disease, vol. 13, no. 4, pp. 421-435, 2008.

[22] W. R. Tyor, J. D. Glass, J. W. Griffin et al., "Cytokine expression in the brain during the acquired immunodeficiency syndrome," Annals of Neurology, vol. 31, no. 4, pp. 349-360, 1992.

[23] P. M. Polgreen, S. L. Fultz, A. C. Justice et al., "Association of hypocholesterolaemia with hepatitis $\mathrm{C}$ virus infection in HIV-infected people," HIV Medicine, vol. 5, no. 3, pp. 144150, 2004.

[24] E. C. M. van Gorp, C. Suharti, A. T. A. Mairuhu et al., "Changes in the plasma lipid profile as a potential predictor of clinical outcome in dengue hemorrhagic fever," Clinical Infectious Diseases, vol. 34, no. 8, pp. 1150-1153, 2002. 
[25] R. A. Memon, C. Grunfeld, A. H. Moser, and K. R. Feingold, "Tumor necrosis factor mediates the effects of endotoxin on cholesterol and triglyceride metabolism in mice," Endocrinology, vol. 132, no. 5, pp. 2246-2253, 1993.

[26] I. P. Singh, A. K. Chopra, D. H. Coppenhaver, G. M. Ananatharamaiah, and S. Baron, "Lipoproteins account for part of the broad non-specific antiviral activity of human serum," Antiviral Research, vol. 42, no. 3, pp. 211-218, 1999.

[27] N. de Bont, M. G. Netea, P. N. M. Demacker et al., "Apolipoprotein E knock-out mice are highly susceptible to endotoxemia and Klebsiella pneumoniae infection," Journal of Lipid Research, vol. 40, no. 4, pp. 680-685, 1999.

[28] J. R. Lynch, W. Tang, H. Wang et al., "APOE genotype and an ApoE-mimetic peptide modify the systemic and central nervous system inflammatory response," The Journal of Biological Chemistry, vol. 278, no. 49, pp. 48529-48533, 2003.

[29] N. De Bont, M. G. Netea, P. N. Demacker, B. J. Kullberg, J. W. van der Meer, and A. F. Stalenhoef, "Apolipoprotein E-deficient mice have an impaired immune response to Klebsiella pneumoniae," European Journal of Clinical Investigation, vol. 30, no. 9, pp. 818-822, 2000.

[30] M. van Oosten, P. C. N. Rensen, E. S. van Amersfoort et al., "Apolipoprotein E protects against bacterial lipopolysaccharide-induced lethality: a new therapeutic approach to treat Gram-negative sepsis," The Journal of Biological Chemistry, vol. 276, no. 12, pp. 8820-8824, 2001.

[31] O. M. Kattan, F. B. Kasravi, E. L. Elford, M. T. Schell, and H. W. Harris, "Apolipoprotein E-mediated immune regulation in sepsis," Journal of Immunology, vol. 181, no. 2, pp. 13991408, 2008.

[32] G. W. Martens, M. C. Arikan, J. Lee, F. Ren, T. Vallerskog, and H. Kornfeld, "Hypercholesterolemia impairs immunity to tuberculosis," Infection and Immunity, vol. 76, no. 8, pp. 3464-3472, 2008.

[33] T. D. Burt, B. K. Agan, V. C. Marconi et al., "Apolipoprotein (apo) E4 enhances HIV-1 cell entry in vitro, and the APOE $\varepsilon 4 / \varepsilon 4$ genotype accelerates HIV disease progression," Proceedings of the National Academy of Sciences of the United States of America, vol. 105, no. 25, pp. 8718-8723, 2008.

[34] R. F. Itzhaki, M. Wozniak, C. Dobson, and W. R. Lin, "ApoEviral interactions," Nature Medicine, vol. 4, no. 12, p. 1344, 1998.

[35] E. H. Corder, K. Robertson, L. Lannfelt et al., "HIV-infected subjects with the E4 allele for APOE have excess dementia and peripheral neuropathy," Nature Medicine, vol. 4, no. 10, pp. 1182-1184, 1998.

[36] R. F. Itzhaki, W. R. Lin, D. Shang, G. K. Wilcock, B. Faragher, and G. A. Jamieson, "Herpes simplex virus type 1 in brain and risk of Alzheimer's disease," The Lancet, vol. 349, no. 9047, pp. 241-244, 1997.

[37] R. F. Itzhaki and M. A. Wozniak, "Herpes simplex virus type 1, apolipoprotein E, and cholesterol: a dangerous liaison in Alzheimer's disease and other disorders," Progress in Lipid Research, vol. 45, no. 1, pp. 73-90, 2006.

[38] D. A. Price, M. F. Bassendine, S. M. Norris et al., "Apolipoprotein $\varepsilon 3$ allele is associated with persistent hepatitis $\mathrm{C}$ virus infection," Gut, vol. 55, no. 5, pp. 715-718, 2006.

[39] T. Hishiki, Y. Shimizu, R. Tobita et al., "Infectivity of hepatitis $\mathrm{C}$ virus is influenced by association with apolipoprotein $\mathrm{E}$ isoforms," Journal of Virology, vol. 84, no. 22, pp. 12048 12057, 2010.
[40] C. Fabris, C. Vandelli, P. Toniutto et al., "Apolipoprotein E genotypes modulate fibrosis progression in patients with chronic hepatitis $\mathrm{C}$ and persistently normal transaminases," Journal of Gastroenterology and Hepatology, vol. 26, no. 2, pp. 328-333, 2011.

[41] Z. Yin, C. Xiong, Y. Wang, X. Zhou, and S.-K. Yan, "Investigation of the relationship between apolipoprotein $\mathrm{E}$ gene polymorphisms and hepatitis B virus infection in northern China," Clinical Chemistry and Laboratory Medicine, vol. 48, no. 12, pp. 1803-1807, 2010.

[42] D. Baitsch, H. H. Bock, T. Engel et al., "Apolipoprotein E induces antiinflammatory phenotype in macrophages," Arteriosclerosis, Thrombosis, and Vascular Biology, vol. 31, no. 5, pp. 1160-1168, 2011.

[43] Y. Zhu, A. Kodvawala, and D. Y. Hui, "Apolipoprotein E inhibits Toll-like receptor (TLR)-3- and TLR-4-mediated macrophage activation through distinct mechanisms," The Biochemical Journal, vol. 428, no. 1, pp. 47-54, 2010.

[44] J. R. Lynch, D. Morgan, J. Mance, W. D. Matthew, and D. T. Laskowitz, "Apolipoprotein E modulates glial activation and the endogenous central nervous system inflammatory response," Journal of Neuroimmunology, vol. 114, no. 1-2, pp. 107-113, 2001.

[45] D. T. Laskowitz, A. D. Thekdi, S. D. Thekdi et al., "Downregulation of microglial activation by apolipoprotein $\mathrm{E}$ and apoEmimetic peptides," Experimental Neurology, vol. 167, no. 1, pp. 74-85, 2001.

[46] J. Zhu, E. Mix, and H. Link, "Cytokine production and the pathogenesis of experimental autoimmune neuritis and Gulllain-Barré syndrome," Journal of Neuroimmunology, vol. 84, no. 1, pp. 40-52, 1998.

[47] J. Zhu, X. F. Bai, E. Mix, and H. Link, "Cytokine dichotomy in peripheral nervous system influences the outcome of experimental allergic neuritis: dynamics of mRNA expression for IL-1 $\beta$, IL-6, IL-10, IL-12, TNF- $\alpha$, TNF- $\beta$, and cytolysin," Clinical Immunology and Immunopathology, vol. 84, no. 1, pp. 85-94, 1997.

[48] J. Zhu, X. F. Bai, E. Mix, and H. Link, "Experimental allergic neuritis: cytolysin mRNA expression is upregulated in lymph node cells during convalescence," Journal of Neuroimmunology, vol. 78, no. 1-2, pp. 108-116, 1997.

[49] L. Bao, J. U. Lindgren, P. van der Meide, S. W. Zhu, H. G. Ljunggren, and J. Zhu, "The critical role of IL12 p40 in initiating, enhancing, and perpetuating pathogenic events in murine experimental autoimmune neuritis," Brain Pathology, vol. 12, no. 4, pp. 420-429, 2002.

[50] F. Nicoletti, A. Créange, D. Orlikowski et al., "Macrophage migration inhibitory factor (MIF) seems crucially involved in Guillain-Barré syndrome and experimental allergic neuritis," Journal of Neuroimmunology, vol. 168, no. 1-2, pp. 168-174, 2005.

[51] S. Yu, Z. Chen, E. Mix et al., "Neutralizing antibodies to IL-18 ameliorate experimental autoimmune neuritis by counterregulation of autoreactive Th1 responses to peripheral myelin antigen," Journal of Neuropathology and Experimental Neurology, vol. 61, no. 7, pp. 614-622, 2002.

[52] G. Deretzi, L. P. Zou, S. H. Pelidou et al., "Nasal administration of recombinant rat IL-4 ameliorates ongoing experimental autoimmune neuritis and inhibits demyelination," Journal of Autoimmunity, vol. 12, no. 2, pp. 81-89, 1999.

[53] X. F. Bai, J. Zhu, G. X. Zhang et al., "IL-10 suppresses experimental autoimmune neuritis and down-regulates $\mathrm{T}(\mathrm{H}) 1$-type immune responses," Clinical Immunology and Immunopathology, vol. 83, no. 2, pp. 117-126, 1997. 
[54] J. Leipe, M. Grunke, C. Dechant et al., "Role of Th17 cells in human autoimmune arthritis," Arthritis and Rheumatism, vol. 62, no. 10, pp. 2876-2885, 2010.

[55] M. O. Li, Y. Y. Wan, and R. A. Flavell, "T cell-produced transforming growth factor- $\beta 1$ controls $\mathrm{T}$ cell tolerance and regulates Th1- and Th17-cell differentiation," Immunity, vol. 26, no. 5, pp. 579-591, 2007.

[56] M. Yin, L. Zhang, X. M. Sun, L. F. Mao, and J. Pan, "Lack of apoE causes alteration of cytokines expression in young mice liver," Molecular Biology Reports, vol. 37, no. 4, pp. 20492054, 2010.

[57] K. Ali, M. Middleton, E. Puré, and D. J. Rader, "Apolipoprotein E suppresses the type I inflammatory response in vivo," Circulation Research, vol. 97, no. 9, pp. 922-927, 2005.

[58] C. Tenger and X. Zhou, "Apolipoprotein E modulates immune activation by acting on the antigen-presenting cell," Immunology, vol. 109, no. 3, pp. 392-397, 2003.

[59] X. Zhou, G. Paulsson, S. Stemme, and G. K. Hansson, "Hypercholesterolemia is associated with a T helper (Th) 1/Th2 switch of the autoimmune response in atherosclerotic apo E-knockout mice," The Journal of Clinical Investigation, vol. 101, no. 8, pp. 1717-1725, 1998.

[60] P. Davenport and P. G. Tipping, "The role of interleukin-4 and interleukin-12 in the progression of atherosclerosis in apolipoprotein E-deficient mice," American Journal of Pathology, vol. 163, no. 3, pp. 1117-1125, 2003.

[61] A. Kawamura, D. Baitsch, R. Telgmann et al., "Apolipoprotein $\mathrm{E}$ interrupts interleukin-1 $\beta$ signaling in vascular smooth muscle cells," Arteriosclerosis, Thrombosis, and Vascular Biology, vol. 27, no. 7, pp. 1610-1617, 2007.

[62] D. J. Stuehr, H. J. Cho, . Nyoun Soo Kwon, M. F. Weise, and C. F. Nathan, "Purification and characterization of the cytokineinduced macrophage nitric oxide synthase: an FAD- and FMN-containing flavoprotein," Proceedings of the National Academy of Sciences of the United States of America, vol. 88, no. 17, pp. 7773-7777, 1991.

[63] M. P. Vitek, J. Snell, H. Dawson, and C. A. Colton, "Modulation of nitric oxide production in human macrophages by apolipoprotein-E and amyloid-beta peptide," Biochemical and Biophysical Research Communications, vol. 240, no. 2, pp. 391-394, 1997.

[64] C. A. Colton, M. Czapiga, J. Snell-Callanan, O. N. Chernyshev, and M. P. Vitek, "Apolipoprotein E acts to increase nitric oxide production in macrophages by stimulating arginine transport," Biochimica et Biophysica Acta, vol. 1535, no. 2, pp. 134-144, 2001.

[65] C. A. Colton, C. M. Brown, D. Cook et al., "APOE and the regulation of microglial nitric oxide production: a link between genetic risk and oxidative stress," Neurobiology of Aging, vol. 23, no. 5, pp. 777-785, 2002.

[66] C. A. Colton, L. K. Needham, C. Brown et al., "APOE genotype-specific differences in human and mouse macrophage nitric oxide production," Journal of Neuroimmunology, vol. 147, no. 1-2, pp. 62-67, 2004.

[67] I. Maezawa, M. Nivison, K. S. Montine, N. Maeda, and T. J. Montine, "Neurotoxicity from innate immune response is greatest with targeted replacement of E4 allele of apolipoprotein E gene and is mediated by microglial p38MAPK," The FASEB Journal, vol. 20, no. 6, pp. 797-799, 2006.

[68] C. M. Brown, Q. Xu, N. Okhubo, M. P. Vitek, and C. A. Colton, "Androgen-mediated immune function is altered by the apolipoprotein E gene," Endocrinology, vol. 148, no. 7, pp. 3383-3390, 2007.
[69] G. Meyer zu Hörste, W. Hu, H. P. Hartung, H. C. Lehmann, and B. C. Kieseier, "The immunocompetence of Schwann cells," Muscle and Nerve, vol. 37, no. 1, pp. 3-13, 2008.

[70] R. S. Duan, T. Jin, X. Yang, E. Mix, A. Adem, and J. Zhu, "Apolipoprotein E deficiency enhances the antigenpresenting capacity of Schwann cells," Glia, vol. 55, no. 7, pp. 772-776, 2007.

[71] S. Yu, R. S. Duan, Z. Chen et al., "Increased susceptibility to experimental autoimmune neuritis after upregulation of the autoreactive $\mathrm{T}$ cell response to peripheral myelin antigen in apolipoprotein E-deficient mice," Journal of Neuropathology and Experimental Neurology, vol. 63, no. 2, pp. 120-128, 2004.

[72] J. J. Xie, J. Wang, T. T. Tang et al., "The Th17/Treg functional imbalance during atherogenesis in $\mathrm{ApoE}^{-/-}$mice," Cytokine, vol. 49, no. 2, pp. 185-193, 2010.

[73] E. Smith, K. M. R. Prasad, M. Butcher et al., "Blockade of interleukin-17A results in reduced atherosclerosis in apolipoprotein E-deficient mice," Circulation, vol. 121, no. 15, pp. 1746-1755, 2010.

[74] F. Q. Li, G. D. Sempowski, S. E. McKenna, D. T. Laskowitz, C. A. Colton, and M. P. Vitek, "Apolipoprotein E-derived peptides ameliorate clinical disability and inflammatory infiltrates into the spinal cord in a murine model of multiple sclerosis," Journal of Pharmacology and Experimental Therapeutics, vol. 318, no. 3, pp. 956-965, 2006.

[75] H. L. Zhang, J. Wu, and J. Zhu, "The immune-modulatory role of apolipoprotein e with emphasis on multiple sclerosis and experimental autoimmune encephalomyelitis," Clinical and Developmental Immunology, vol. 2010, Article ID 186813, 2010.

[76] K. Singh, R. Chaturvedi, D. P. Barry et al., “The apolipoprotein E-mimetic peptide COG112 inhibits NF- $\kappa$ B signaling, proinflammatory cytokine expression, and disease activity in murine models of colitis," The Journal of Biological Chemistry, vol. 286, no. 5, pp. 3839-3850, 2011.

[77] S. Schulte, G. K. Sukhova, and P. Libby, "Genetically programmed biases in Th1 and Th2 immune responses modulate atherogenesis," American Journal of Pathology, vol. 172, no. 6, pp. 1500-1508, 2008.

[78] L. Jofre-Monseny, A. M. Minihane, and G. Rimbach, "Impact of apoE genotype on oxidative stress, inflammation and disease risk," Molecular Nutrition and Food Research, vol. 52, no. 1, pp. 131-145, 2008.

[79] U. K. Misra, C. L. Adlakha, G. Gawdi, M. K. McMillian, S. V. Pizzo, and D. T. Laskowitz, "Apolipoprotein E and mimetic peptide initiate a calcium-dependent signaling response in macrophages," Journal of Leukocyte Biology, vol. 70, no. 4, pp. 677-683, 2001.

[80] J. Ruiz, D. Kouiavskaia, M. Migliorini et al., "The apoE isoform binding properties of the VLDL receptor reveal marked differences from LRP and the LDL receptor," Journal of Lipid Research, vol. 46, no. 8, pp. 1721-1731, 2005.

[81] M. P. Vitek, C. M. Brown, and C. A. Colton, "APOE genotype-specific differences in the innate immune response," Neurobiology of Aging, vol. 30, no. 9, pp. 1350-1360, 2009.

[82] L. M. Tsoi, K. Y. Wong, Y. M. Liu, and Y. Y. Ho, "Apoprotein $\mathrm{E}$ isoform-dependent expression and secretion of proinflammatory cytokines TNF- $\alpha$ and IL-6 in macrophages," Archives of Biochemistry and Biophysics, vol. 460, no. 1, pp. 33-40, 2007.

[83] L. Jofre-Monseny, A. Loboda, A. E. Wagner et al., "Effects of apoE genotype on macrophage inflammation and heme 
oxygenase-1 expression," Biochemical and Biophysical Research Communications, vol. 357, no. 1, pp. 319-324, 2007.

[84] D. T. Laskowitz, S. Goel, E. R. Bennett, and W. D. Matthew, "Apolipoprotein E suppresses glial cell secretion of TNF $\alpha$," Journal of Neuroimmunology, vol. 76, no. 1-2, pp. 70-74, 1997.

[85] S. W. Barger and A. D. Harmon, "Microglial activation by alzhelmer amyloid precursor protein and modulation by apolipoprotein E," Nature, vol. 388, no. 6645, pp. 878-881, 1997.

[86] L. Guo, M. J. LaDu, and L. J. van Eldik, "A dual role for apolipoprotein e in neuroinflammation: anti- and proinflammatory activity," Journal of Molecular Neuroscience, vol. 23, no. 3, pp. 205-212, 2004.

[87] C. Boesch-Saadatmandi, S. Wolffram, A. M. Minihane, and G. Rimbach, "Effect of apoE genotype and dietary quercetin on blood lipids and TNF- $\alpha$ levels in apoE3 and apoE4 targeted gene replacement mice," British Journal of Nutrition, vol. 101, no. 10, pp. 1440-1443, 2009.

[88] S. Chen, N. T. Averett, A. Manelli, M. J. LaDu, W. May, and M. D. Ard, "Isoform-specific effects of apolipoprotein E on secretion of inflammatory mediators in adult rat microglia," Journal of Alzheimer's Disease, vol. 7, no. 1, pp. 25-35, 2005.

[89] I. Maezawa, N. Maeda, T. J. Montine, and K. S. Montine, "Apolipoprotein E-specific innate immune response in astrocytes from targeted replacement mice," Journal of Neuroinflammation, vol. 3, article no. 10, 2006.

[90] I. Tesseur, H. Zhang, W. Brecht et al., "Bioactive TGF- $\beta$ can associate with lipoproteins and is enriched in those containing apolipoprotein E3," Journal of Neurochemistry, vol. 110, no. 4, pp. 1254-1262, 2009.

[91] G. Ophir, N. Amariglio, J. Jacob-Hirsch, R. Elkon, G. Rechavi, and D. M. Michaelson, "Apolipoprotein E4 enhances brain inflammation by modulation of the NF- $\kappa \mathrm{B}$ signaling cascade," Neurobiology of Disease, vol. 20, no. 3, pp. 709-718, 2005.

[92] H. Wang, D. J. Christensen, M. P. Vitek, P. M. Sulivan, and D. T. Laskowitz, "APOE genotype affects outcome in a murine model of sepsis: implications for a new treatment strategy," Anaesthesia and Intensive Care, vol. 37, no. 1, pp. 38-45, 2009.

[93] P. Olgiati, A. Politis, P. Malitas et al., "APOE epsilon4 allele and cytokine production in Alzheimer's disease," International Journal of Geriatric Psychiatry, vol. 25, no. 4, pp. 338-344, 2010.

[94] D. N. Tziakas, G. K. Chalikias, C. O. Antonoglou et al., "Apolipoprotein E genotype and circulating interleukin-10 levels in patients with stable and unstable coronary artery disease," Journal of the American College of Cardiology, vol. 48, no. 12, pp. 2471-2481, 2006.

[95] C. M. Bojanowski, D. Shen, E. Y. Chew et al., "An apolipoprotein $\mathrm{E}$ variant may protect against age-related macular degeneration through cytokine regulation," Environmental and Molecular Mutagenesis, vol. 47, no. 8, pp. 594-602, 2006.

[96] C. M. Brown, E. Choi, Q. Xu, M. P. Vitek, and C. A. Colton, "The APOE4 genotype alters the response of microglia and macrophages to $17 \beta$-estradiol," Neurobiology of Aging, vol. 29, no. 12, pp. 1783-1794, 2008.

[97] K. Brand, N. Mackman, and L. K. Curtiss, "Interferon$\gamma$ inhibits macrophage apolipoprotein E production by posttranslational mechanisms," The Journal of Clinical Investigation, vol. 91, no. 5, pp. 2031-2039, 1993.

[98] J. Saura, V. Petegnief, X. Wu, Y. Liang, and S. M. Paul, "Microglial apolipoprotein E and astroglial apolipoprotein J expression in vitro: opposite effects of lipopolysaccharide,"
Journal of Neurochemistry, vol. 85, no. 6, pp. 1455-1467, 2003.

[99] M. Starck, P. Bertrand, S. Pépin, F. Schiele, G. Siest, and M. M. Galteau, "Effects of pro-inflammatory cytokines on apolipoprotein E secretion by a human astrocytoma cell line (CCF-STTG1)," Cell Biochemistry and Function, vol. 18, no. 1, pp. 9-16, 2000.

[100] S. H. Zuckerman, G. F. Evans, and L. O’Neal, “Cytokine regulation of macrophage apo E secretion: opposing effects of GM-CSF and TGF- $\beta$," Atherosclerosis, vol. 96, no. 2-3, pp. 203-214, 1992.

[101] J. Levin-Allerhand, B. S. McEwen, C. E. Lominska, D. B. Lubahn, K. S. Korach, and J. D. Smith, "Brain region-specific up-regulation of mouse apolipoprotein E by pharmacological estrogen treatments," Journal of Neurochemistry, vol. 79, no. 4, pp. 796-803, 2001.

[102] N. Srivastava, M. Averna, R. C. Lin, K. S. Korach, D. B. Lubahn, and G. Schonfeld, "Estrogen up-regulates apolipoprotein E (ApoE) gene expression by increasing ApoE mRNA in the translating pool via the estrogen receptor $\alpha$ mediated pathway," The Journal of Biological Chemistry, vol. 272, no. 52, pp. 33360-33366, 1997.

[103] D. J. Stone, I. Rozovsky, T. E. Morgan, C. P. Anderson, H. Hajian, and C. E. Finch, "Astrocytes and microglia respond to estrogen with increased apoE mRNA in vivo and in vitro," Experimental Neurology, vol. 143, no. 2, pp. 313-318, 1997.

[104] R. Aleong, J. F. Blain, and J. Poirier, "Pro-inflammatory cytokines modulate glial apolipoprotein E secretion," Current Alzheimer Research, vol. 5, no. 1, pp. 33-37, 2008.

[105] S. M. Hofmann, D. Perez-Tilve, T. M. Greer et al., "Defective lipid delivery modulates glucose tolerance and metabolic response to diet in apolipoprotein E-deficient mice," Diabetes, vol. 57, no. 1, pp. 5-12, 2008.

[106] L. Yue, N. Rasouli, G. Ranganathan, P. A. Kern, and T. Mazzone, "Divergent effects of peroxisome proliferatoractivated receptor $\gamma$ agonists and tumor necrosis factor $\alpha$ on adipocyte ApoE expression," The Journal of Biological Chemistry, vol. 279, no. 46, pp. 47626-47632, 2004.

[107] L. Yue, J. W. Christman, and T. Mazzone, "Tumor necrosis factor- $\alpha$-mediated suppression of adipocyte apolipoprotein $\mathrm{E}$ gene transcription: primary role for the nuclear factor (NF)$\kappa \mathrm{B}$ pathway and NF $\kappa \mathrm{B}$ p50," Endocrinology, vol. 149, no. 8, pp. 4051-4058, 2008.

[108] C. A. Colton, C. M. Brown, and M. P. Vitek, "Sex steroids, APOE genotype and the innate immune system," Neurobiology of Aging, vol. 26, no. 3, pp. 363-372, 2005.

[109] D. O'Toole and W. C. Love, "Interferon- $\beta-1 \mathrm{~b}$ and interferon$\gamma$ have similar inhibitory effects on apolipoprotein-E production in the monocyte/macrophage," Multiple Sclerosis, vol. 8, no. 2, pp. 124-129, 2002.

[110] N. N. Singh and D. P. Ramji, “Transforming growth factor$\beta$-induced expression of the apolipoprotein E gene requires c-Jun N-terminal kinase, p38 kinase, and casein kinase 2," Arteriosclerosis, Thrombosis, and Vascular Biology, vol. 26, no. 6, pp. 1323-1329, 2006. 


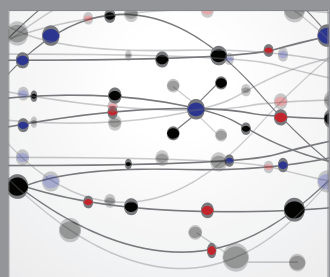

The Scientific World Journal
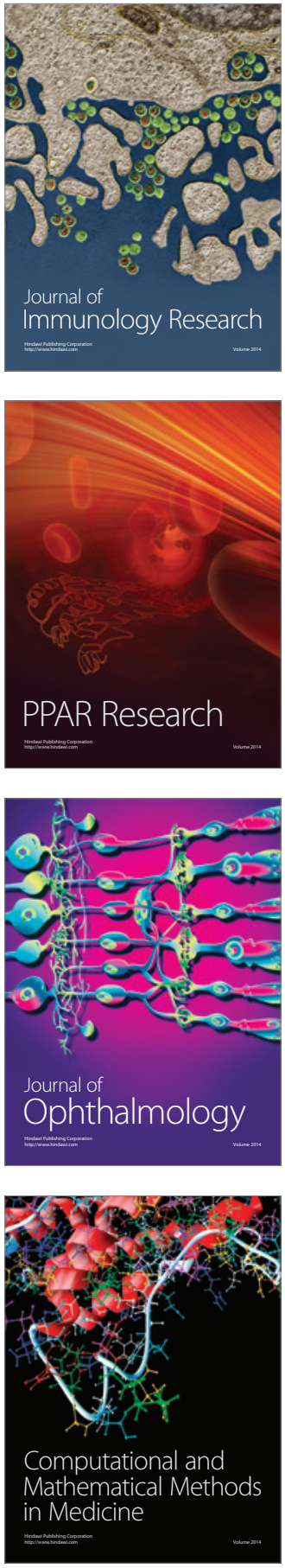

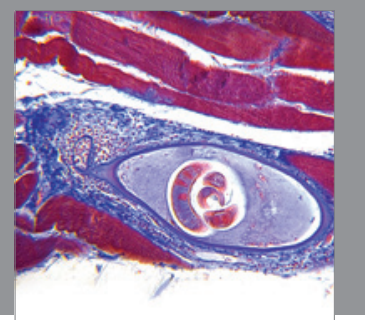

Gastroenterology

Research and Practice
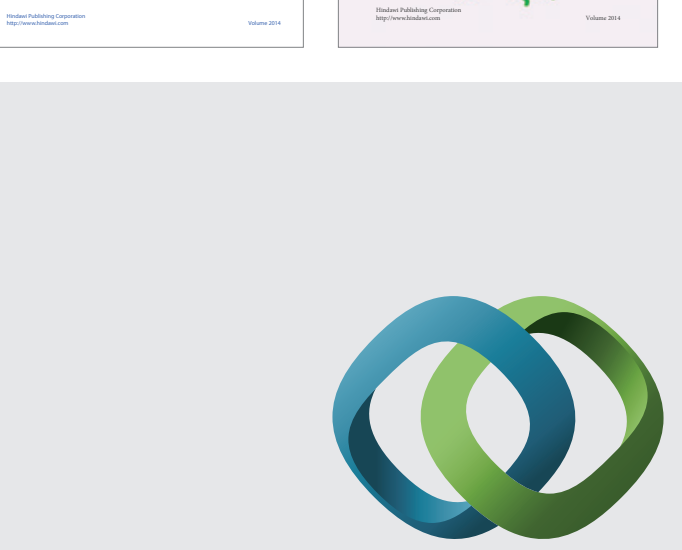

\section{Hindawi}

Submit your manuscripts at

http://www.hindawi.com
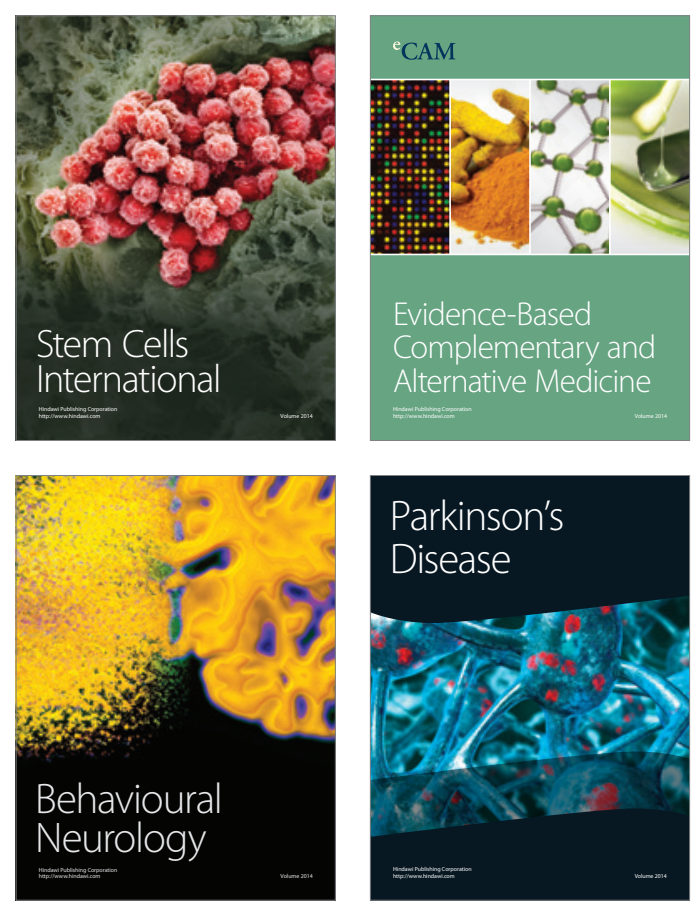

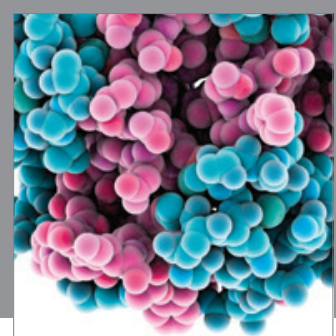

Journal of
Diabetes Research

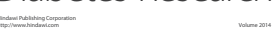

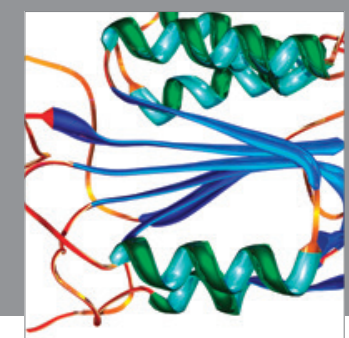

Disease Markers
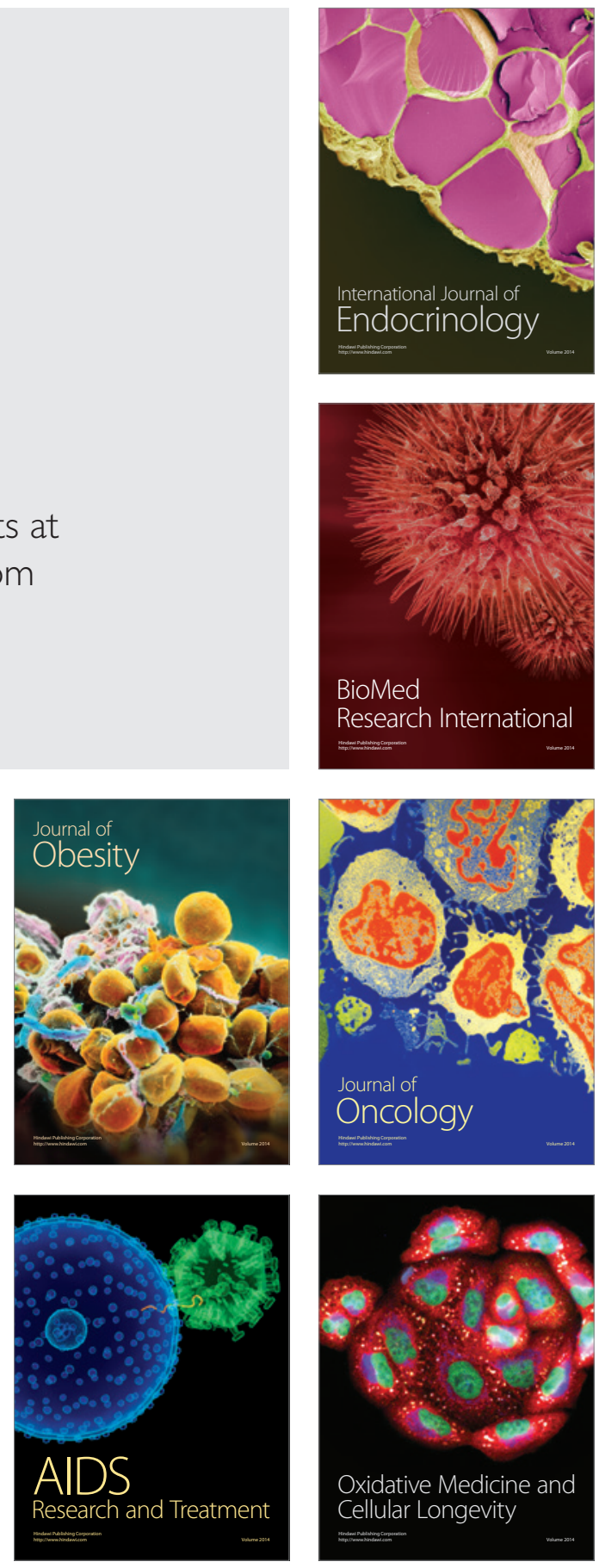